\title{
COMPARING THE EFFICIENCY OF 2\% LIDOCAINE AND 4\% ARTICAINE AS A LOCAL ANESTHETIC AGENT IN CHILDREN
}

\author{
MANISHA NAIR, GANESH JEEVANANDAN*, MEENAKSHI MOHAN \\ Department of Pediatric and Preventive Dentistry, Saveetha Dental College, Chennai, Tamil Nadu, India. \\ Email: helloganz@gamil.com
}

Received: 27 December 2017, Revised and Accepted: 01 February 2018

\begin{abstract}
Objective: The objective of this study is to compare the anesthetic efficiency of conventional $2 \%$ lidocaine with $4 \%$ articaine when infiltrated in the maxillary arch for pediatric patients during pulp therapy and extraction.

Methodology: A randomized control trial was done with 45 children $(n=45)$ of the age group $4-8$ years. The children were randomly allotted to two experimental groups. Group A - Children received 2\% Lidocaine HCL infilteration both buccally and palatally, Group B - Children received 2\% Lidocaine infilteration buccally and Group C - Children received 4\% Articaine infilteration baccally as local anesthetic agent. Post treatment, pain assessment was done using visual analog scale.
\end{abstract}

Results: Articaine group had significantly lower pain scores when compared to the lidocaine group.

Conclusion: Articaine infiltration can be considered as an effective alternative for the conventional lidocaine infiltration.

Keywords: Articaine, Lidocaine, Pain assessment, Visual analog scale.

(C) 2018 The Authors. Published by Innovare Academic Sciences Pvt Ltd. This is an open access article under the CC BY license (http://creativecommons. org/licenses/by/4. 0/) DOI: http://dx.doi.org/10.22159/ajpcr.2018.v11i5.24440

\section{INTRODUCTION}

Pain control in pediatric dentistry is an important contributor to reduce the child's anxiety. Children tend to have greater emotional outbursts when compared to adults during medical and dental procedures [1]. Thus, managing children during an invasive procedure is a challenging task. Local anesthetics play a part and parcel of dentistry in pain control techniques [2]. Advancements in local anesthetics have taken its course way back from 1884 when cocaine was used for anesthetic purposes to lidocaine from the year 1943. Lidocaine was first synthesized by a Swedish Chemist Nils Lofgren, which still continues to be a benchmark in local anesthetic evolution. $2 \%$ lidocaine HCL is considered as the reference standard for comparing the other local anesthetics till date. In the succeeding years, other amide local anesthetics (prilocaine, bupivacaine, etc.) were introduced [3]. At present, the local anesthetic armamentarium consists of anesthetic agents whose duration of action ranges from $20 \mathrm{~min}$ (mepivacaine) to $3 \mathrm{~h}$ (bupivacaine with adrenaline) [2].

In the year 1969, a new local anesthetic drug, articaine was discovered by Rusching et al. It was first named as carticaine, but then its generic name was renamed as articaine in the year 1984 [4]. Since its time of invention, articaine is being the subject of interest among the dentists. Articaine is considered to be a unique local anesthetic agent as it is the only local anesthetic with a thiophene ring in the place of the benzene ring, which increases its liposolubility [5]. Due to this, biotransformation of articaine takes place in both plasma and liver and is excreted through the kidneys [6]. Articaine penetrates well into the tissues and diffuses efficiently. Its plasma protein binding capacity is $95 \%$ higher than the other local anesthetics [5]. The mechanism of action of articaine is similar to that of lidocaine [2]. Addition of a vasopressor to lidocaine and articaine would produce a localized vasoconstriction, thus retarding the absorption of local anesthetic agents, leading to a prolonged action [2]. Hence, adrenaline is being added to both articaine and lidocaine to intensify its property. Clinical trials conducted using various concentrations of articaine with and without vasopressor showed that $4 \%$ articaine with adrenaline provide significantly greater properties when compared to $1 \%, 2 \%$, and $3 \%$ articaine [7-9].

Hence, 2\% lidocaine HCL and 4\% articaine HCL were used in this study. Although various studies have been conducted so far to check for the efficiency of articaine as a local anesthetic agent and also to compare its properties and advantages over lidocaine, similar studies on pediatric patients are quite less. Thus, this study aims in assessing the efficiency of articaine over lidocaine among the pediatric patients and also find if articaine is effective in providing palatal anesthesia when infiltrated buccally.

\section{METHODOLOGY}

The research protocol and informed consent were approved by the ethical committee board of the institution. Clinical procedures were explained in detail to the patient's parents/caregivers. Informed consent was obtained from every patient included in the study prior treatment. A randomized control trial was conducted among 45 children of the age group 6-9 years, requiring extraction of maxillary primary molars. Only Frankel's definitely positive and positive children with no medical history were included in the study. Children with negative behavior, non-vital teeth, and medical complications were excluded from the study. A total of 45 children were divided randomly into three groups as follows:

Group A (control group) - $1.8 \mathrm{ml}$ of $2 \%$ lidocaine HCL with adrenaline

$1: 2,00,000$ was injected buccally $(1.5 \mathrm{ml})$ and palatally $(0.3 \mathrm{ml})$ Group B - $1.8 \mathrm{ml}$ of $2 \%$ lidocaine injected buccally Group C - $1.8 \mathrm{ml}$ of $4 \%$ articaine injected buccally.

Children in Group A received both buccal and palatal injection, whereas children in Group B received only buccal injection.

The mucobuccal fold corresponding to the site of injection was dried with gauze, and a topical anesthetic gel ( $2 \%$ benzocaine) was applied. In the control group, $1.8 \mathrm{ml}$ ( $1.5 \mathrm{ml}$ buccally and $0.3 \mathrm{ml}$ palatally) of $2 \%$ 


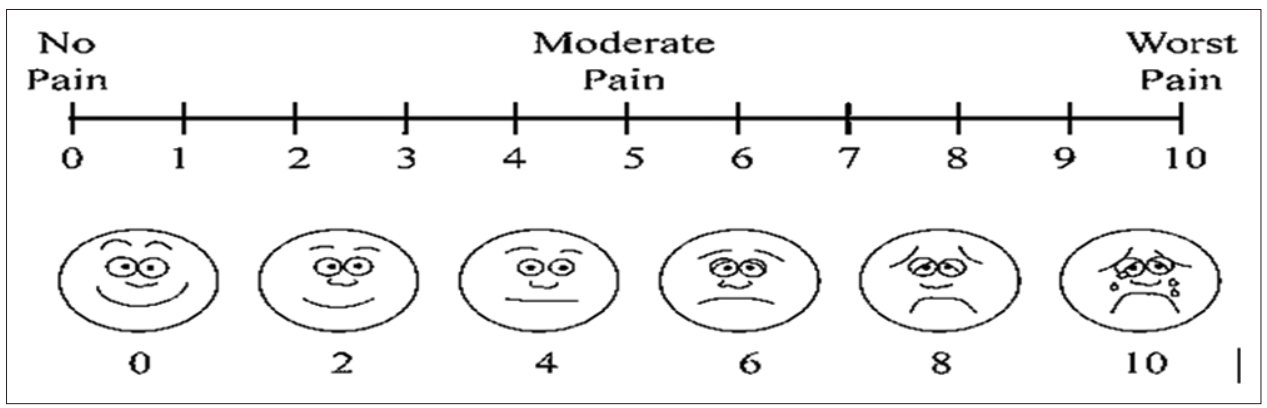

Fig. 1: Visual analog scale used in the study

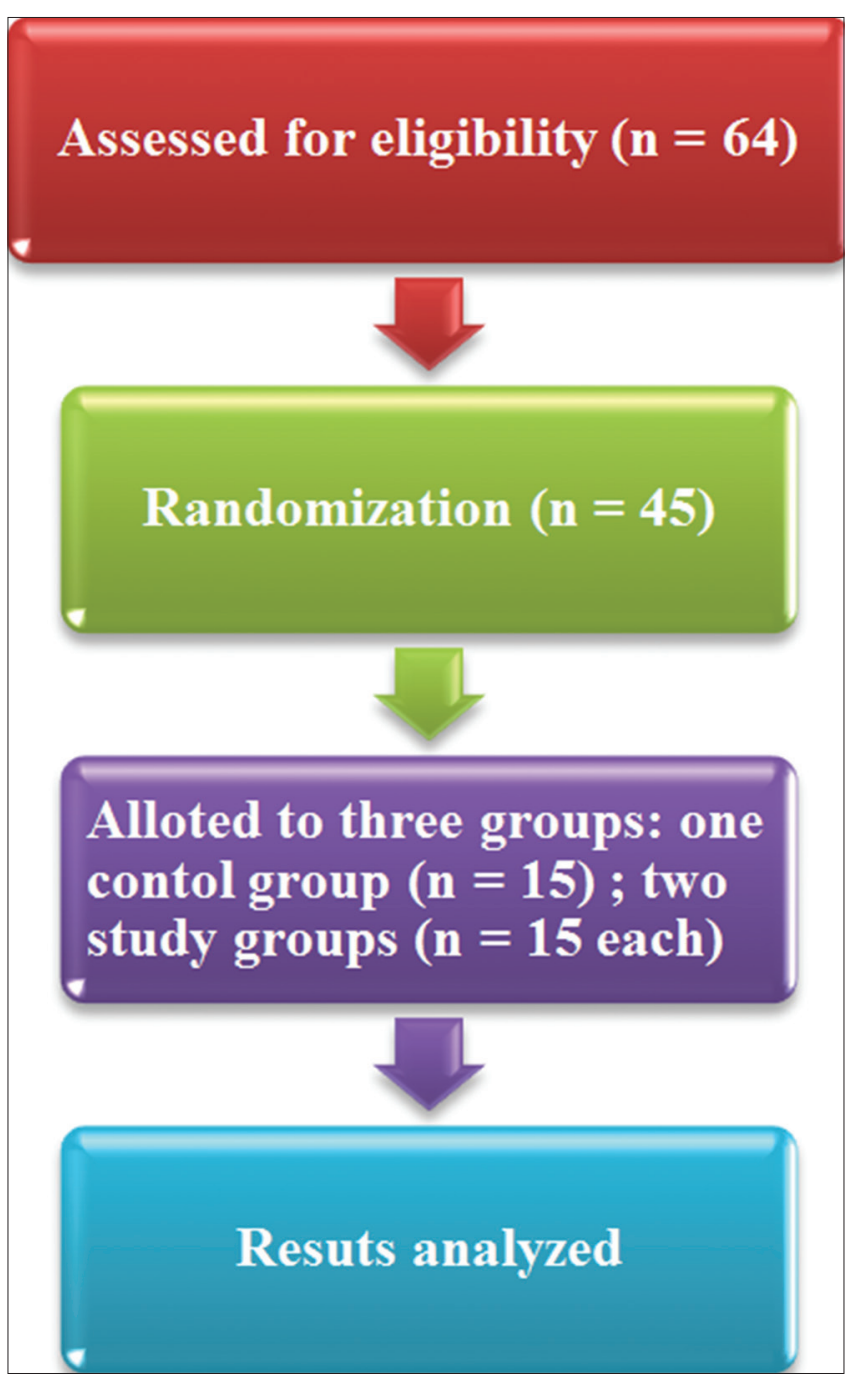

Fig. 2: Flow diagram of study methodology

lidocaine solution was injected using a 27-gauge needle under sterile condition. A similar procedure was followed in the other two groups, except that, $1.8 \mathrm{ml}$ of $2 \%$ lidocaine was injected buccally in Group B patients and $1.8 \mathrm{ml}$ of $4 \%$ articaine was injected buccally in Group C patients. Objective signs of numbness were evaluated using a periosteal elevator, first on the contralateral side and then on the anesthetized side after $10 \mathrm{~min}$.

The visual analog scale (VAS) (Fig. 1) was given immediately after the local anesthetic injection and after the extraction to patients belonging to all the three groups for the assessment of pain, and the score was recorded.
Table 1: The comparison of pain scores between the groups during injection and during extraction

\begin{tabular}{llllll}
\hline Intervention & $\mathbf{n}$ & Mean \pm SD & SE & $\mathbf{F}$ & $\mathbf{p}$ \\
\hline $\begin{array}{l}\text { During } \\
\text { injection }\end{array}$ & & & & & \\
1.00 & 15 & $8.1333 \pm 1.76743$ & 0.45635 & & \\
2.00 & 15 & $4.4000 \pm 1.72378$ & 0.44508 & 15.983 & 0.000 \\
3.00 & 15 & $5.0667 \pm 2.25093$ & 0.58119 & & \\
Total & 45 & $5.8667 \pm 2.50091$ & 0.37281 & & \\
During & & & & & \\
extraction & & & & & \\
1.00 & 15 & $1.2000 \pm 1.47358$ & 0.38048 & & \\
2.00 & 15 & $7.2000 \pm 1.47358$ & 0.38048 & 82.053 & 0.000 \\
3.00 & 15 & $1.3333 \pm 1.44749$ & 0.37374 & & \\
Total & 45 & $3.2444 \pm 3.17057$ & 0.47264 & & \\
\hline
\end{tabular}

SD: Standard deviation, SE: Standard error

The materials and methodology has been depicted in brief in the form of a flowchart (Fig. 2).

\section{RESULTS}

The VAS indicated numbers from 0 to 10 (no pain to worst pain). The score $0,2,4,6,8$, and 10 was given as chosen by the child. The results were recorded and tabulated.

The mean value of the pain scores obtained was calculated (Table 1). Pain experienced during extraction showed higher scores on a VAS for $2 \%$ lidocaine when injected only in the buccal aspect (Group B). It showed that there was a significant difference in anesthetic efficiency between $2 \%$ lidocaine and $4 \%$ articaine in maxillary infiltration (Table 2). Articaine although given only buccally provided palatal anesthesia which was not so with lidocaine. Children experienced more pain during palatal injection of lidocaine (Table 2).

ANOVA analysis showing statistical values of results obtained from 45 pediatric patients included in the study.

\section{DISCUSSION}

Lidocaine is the most commonly used local anesthetic agent in dentistry and is considered to be the referral base to check for the efficiency of other local anesthetic agents. It provides pulpal anesthesia for about 1 $\mathrm{h}$ and soft tissue anesthesia for about $3-5 \mathrm{~h}$ [10]. Lidocaine is also used as a topical anesthetic gel and transdermal patch. Various preparation methods have been proposed so far $[11,12]$. When several other local anesthetic agents failed to compete for the standard of lidocaine, articaine was found to be equally efficient and sometimes more efficient than lidocaine since its introduction in the year 1969 [13]. Articaine is the second most commonly used local anesthetic agent in dentistry. It provides pulpal anesthesia for about $1 \mathrm{~h}$ and soft tissue anesthesia for about $2.25 \mathrm{~h}$. Articaine is unique among the other amide local anesthetics because it contains a thiopentone group instead of the benzene ring [14]. Articaine is one of the safest local anesthetics due to 
Table 2: The post hoc Tukey's analysis of the significance level between the groups

\begin{tabular}{|c|c|c|c|c|c|}
\hline Dependent variable & (I) groups & (J) groups & Mean difference (I-J) & SE & $\mathbf{p}$ \\
\hline \multirow[t]{6}{*}{ During injection } & 1.00 & 2.00 & $3.73333^{*}$ & 0.70433 & 0.000 \\
\hline & & 3.00 & $3.06667^{*}$ & 0.70433 & 0.000 \\
\hline & 2.00 & 1.00 & $-3.73333^{*}$ & 0.70433 & 0.000 \\
\hline & & 3.00 & -0.66667 & 0.70433 & 0.614 \\
\hline & 3.00 & 1.00 & $-3.06667^{*}$ & 0.70433 & 0.000 \\
\hline & & 2.00 & 0.66667 & 0.70433 & 0.614 \\
\hline \multirow[t]{5}{*}{ During extraction } & 1.00 & 2.00 & $-6.00000^{*}$ & 0.53492 & 0.000 \\
\hline & 2.00 & 1.00 & $6.00000^{*}$ & 0.53492 & 0.000 \\
\hline & & 3.00 & $5.86667^{*}$ & 0.53492 & 0.000 \\
\hline & 3.00 & 1.00 & 0.13333 & 0.53492 & 0.966 \\
\hline & & 2.00 & $-5.86667^{*}$ & 0.53492 & 0.000 \\
\hline
\end{tabular}

SE: Standard error

its faster metabolic rate. Subsequently, it decreases the risk of systemic toxicity and overdosage. Evidences were claimed that articaine had no toxic reactions when injected among 211 pediatric patients [15]

In the present study, no significant difference in pain perception was seen between the control group and the articaine group (Group C) during extraction procedure. Several studies have reported with similar results [16-20]. There was a significant difference between the articaine group (Group C) and the lidocaine group (Group B) in terms of pain perception. About $4 \%$ articaine group offered a better palatal anesthesia than $2 \%$ lidocaine group with only buccal infiltration. The result of this study goes in concordance with several other studies [21,22], while Ozeç et al. [23] and Mittal et al. [24] disproved the concept of $4 \%$ articaine's efficiency in providing palatal anesthesia only with buccal infiltration. Pain perception in the lidocaine group (Group B) is higher during extraction when compared to the control group. Few studies have reported contradictory results in this aspect [25-27].

Hence, lidocaine infiltration given both buccally and palatally and articaine infiltration given buccally provide an excellent anesthetic effect. Lidocaine when given only buccally has no effect on palatal tissues. In spite of the application of topical local anesthetics before the injections, palatal injections remain to be the most painful of all. Thus, the present study emphasizes at evaluating the anesthetic efficiency of lidocaine and articaine when given only in the buccal aspect.

\section{CONCLUSION}

This study shows that $4 \%$ articaine has better anesthetic efficiency than $2 \%$ lidocaine when only buccal infiltrations are given. This enables the practitioner to avoid palatal injection, causing less pain to the child, thus helping the practitioner in gaining the child's cooperation.

\section{ACKNOWLEDGMENT}

Nil.

\section{CONFLICT OF INTEREST}

Nil.

\section{AUTHORS CONTRIBUTION}

Concept and collection of data-Meenakshi Mohan, Ganesh Jeevanandan Writing the article and critical review of article - Meenakshi Mohan, Manisha Nair

Final approval of the article - Ganesh Jeevanadan

\section{REFERENCES}

1. Le Baron S, Zeltzer L. Assessment of acute pain and anxiety in children and adolescnts by self-reports, obserever reports, and a behaviour checklist. J Consult Clin Psychol 1984;52:729-38.

2. Malamed SF. Handbook of Local Anaesthesia. $4^{\text {th }}$ ed. St. Louis: Mosby; 1997.

3. Meechan JG, Day PF, McMillan AS. Local anesthesia in the palate: A comparison of techniques and solutions. Anesth Prog 2000;47:139.

4. Malamed SF, Gagnon S, Leblanc D. Efficacy of articaine: A new amide local anesthetic. J Am Dent Assoc 2000;131:635-42.

5. Vree TB, Baars AM, van Oss GE, Booij LH. High performance liquid chromatography and preliminary pharmacokinetics of articaine and its 2-carboxy metabolite in human serum and urine. J Chromatogr 1988;424:440-4.

6. Ferger P, Marxkors R. A new anesthetic in dental prosthetics. Dtsch Zahnarztl Z 1973;28:87-9.

7. Winther JE, Nathalang B. Effectivity of a new local analgesic Hoe 40 045. Scand J Dent Res 1972;80:272-8.

8. Winther JE, Patirupanusara B. Evaluation of carticaine-a new local analgesic. Int J Oral Surg 1974;3:422-7.

9. Raab WH, Muller R, Muller HF. Comparative studies on the anesthetic efficiency of $2 \%$ and 4\% articaine. Quint 1990;41:1208-16.

10. Malamed SF, Gagnon S, Leblanc D. Articaine hydrochloride: A study of the safety of a new amide local anesthetic. J Am Dent Assoc 2001;132:177-85.

11. Hasnain MS, Rishishwar P, Ali S. Use of cashew bark exudate gum in the preparation of $4 \%$ lidocaine HCL topical gels. Int J Pharm Pharm Sci 2017;9:146-50

12. Rajab NA, Rassol AA, Assaf SM, Sallam AS. Preparation and evaluation of fentanyl transdremal patches using lidocaine as a model drug and azelaic acid as a penetration enhancer. Int J Pharm Pharm Sci 2014;6:615-20.

13. Haas DA. An update on local anesthetics in dentistry. J Can Dent Assoc 2002;68:546-51

14. Kung J, McDonagh M, Sedgley CM. Does articaine provide an advantage over lidocaine in patients with symptomatic irreversible pulpitis. A systematic review and meta-analysis? J Endod 2015;41:1784-94.

15. Wright GZ, Weinberger SJ, Marti R, Plotzke O. The effectiveness of infiltration anesthesia in the mandibular primary molar region. Pediatr Dent 1991; 13:278-83

16. Luqman U, Janjua OS, Ashfaq M, Irfan H, Mushtaq S, Bilal A. Comparison of articaine and lignocaine for uncomplicated maxillary exodontia. J Coll Physicians Surg Pak 2015;25:181-4.

17. Fan S, Chen WL, Yang ZH, Huang ZQ. Comparison of the efficiencies of permanent maxillary tooth removal performed with single buccal infiltration versus routine buccal and palatal injection. Oral Surg Oral Med Oral Pathol Oral Radiol Endod 2009;107:359-63.

18. Somuri AV, Rai AB, Pillai M. Extraction of permanent maxillary teeth by only buccal infiltration of articaine. J Maxillofac Oral Surg 2013;12:130-2.

19. Oertel R, Rahn R, Kirch W. Clinical pharmacokinetics of articaine. Clin Pharmacokinet 1997;33:417-25.

20. Kolli NK, Nirmala SV, Nuvvula S. The effectiveness of articaine and lidocaine single buccal infiltration versus conventional buccal and palatal injection using lidocaine during primary maxillary molar extraction: A randomized control trial. Anesth Essays Res 2017;11:160.

21. Sharma K, Sharma A, Aseri M, Batta A, Singh V, Pilania D, et al. Maxillary posterior teeth removal without palatal injection-truth or myth: A dilemma for oral surgeons. J Clin Diagn Res 2014;8:ZC01-4. 
22. Darawade DA, Kumar S, Budhiraja S, Mittal M, Mehta TN. A clinical study of efficacy of $4 \%$ articaine hydrochloride versus $2 \%$ lignocaine hydrochloride in dentistry. J Int Oral Health 2014;6:81-3.

23. Ozeç I, Tasdemir U, Gümüs C, Solak O. Is it possible to anesthetize palatal tissues with buccal $4 \%$ articaine injection? J Oral Maxillofac Surg 2010;68:1032-7.

24. Mittal M, Sharma S, Kumar A, Chopra R, Srivastava D. Comparison of anesthetic efficacy of articaine and lidocaine during primary maxillary molar extractions in children. Pediatr Dent 2015;37:520-4.
25. Badcock ME, McCullough MJ. Palatal anaesthesia for the removal of maxillary third molars as practised by oral and maxillofacial surgeons in Australia and New Zealand. Aust Dent J 2007;52:329-32.

26. Sekhar GR, Nagaraju T, Giri K, Nandagopal V, Sudheer R, Sravan. Is palatal injection mandatory prior to extraction of permanent maxillary tooth: A preliminary study. Indian J Dent Res 2011;22:100-2.

27. Yadav S, Verma A, Sachdeva A. Buccal injection of $2 \%$ lidocaine with epinephrine for the removal of maxillary third molars. Anesth Prog 2013;60:95-8 